\title{
Quota hunting of Eurasian lynx in Norway: patterns of hunter selection, hunter efficiency and monitoring accuracy
}

\author{
Erlend B. Nilsen • Henrik Brøseth • John Odden • \\ John D. C. Linnell
}

Received: 26 June 2011 /Revised: 29 September 2011 / Accepted: 4 October 2011 /Published online: 22 October 2011

(C) The Author(s) 2011. This article is published with open access at Springerlink.com

\begin{abstract}
Harvesting large carnivores is often a controversial issue and thus requires a higher precision than other types of recreational harvest. Despite this, management programmes are often initiated based on very limited knowledge about the state of the population and the composition and magnitude of the harvest. Here we analyse patterns of lynx harvest in Norway based on harvest data from 1994 to 2009 . We found clear signs of sex-biased harvest rates, with males generally being more at risk. Further, harvest mortality rates increased with age among males but not among females. In general, the degree of quota filling was high, but there was a tendency for decreasing quota filling with increasing quotas. A population reconstruction of the Norwegian lynx population (1994-2004) based on a modified cohort analysis closely tracked the development in the official monitoring data, suggesting that the managers have access to relatively good information about the development of the population, at least at a larger spatial scale. Despite this, the population trajectory showed large temporal variation, and time lags in the management's decision-making process are a likely cause of the observed patterns in the Norwegian lynx population.
\end{abstract}

Keywords Carnivore management $\cdot$ Sustainable exploitation $\cdot$ Cohort analysis $\cdot$ Lynx lynx $\cdot$ Sex-biased harvest

Communicated by H. Kierdorf

E. B. Nilsen $(\bowtie) \cdot H$. Brøseth $\cdot$ J. Odden $\cdot$ J. D. C. Linnell

Norwegian Institute for Nature Research,

7485 Trondheim, Norway

e-mail: erlend.nilsen@nina.no

\section{Introduction}

Integrating large carnivores into human-dominated landscapes is a necessary, but challenging, conservation activity (Linnell et al. 2001a; 2001b). This might be especially demanding when the focus of conservation moves from saving a species from extinction to trying to establish a sustainable relationship with a recovered population (Swenson et al. 1998), a stage which often involves some extent of lethal control or recreational harvest (Huber et al. 2008; Linnell et al. 2010). The killing of large carnivores is often controversial due to their charismatic nature - conservationists frequently call for hunting bans, whereas the interest groups less positive to carnivore conservation frequently call for higher quotas. The fact that these species are often covered by international legislation such as the European Union's Habitats Directive and the Council of Europe's Bern Convention also opens for the potential for policies to be brought before international courts by various stakeholder groups (Hiedanpää and Bromley 2011; Linnell et al. 2008; Trouwborst 2010). Against this background, carnivore management often has to be precise. This point is made difficult by the fact that knowledge about population sizes and human impacts is hard to obtain in elusive species such as most large carnivores (Treves 2009). In reality, managers must often set harvest quotas based on indices of population abundance and a poor understanding of the relationship between harvest off-take and subsequent population development. The potential for wildlife managers to design harvesting plans that secure the viability of the harvested populations and at the same time meet the public demand for population control has rarely been evaluated.

In areas where carnivore distribution overlaps with that of humans, analysis of cause-specific mortality patterns frequently shows that human-caused mortality dominates 
(Andrèn et al. 2006; Bischof et al. 2009). Quantification of the magnitude and composition of human-induced mortality is thus crucial to our understanding of the effect of such mortality regimes on population dynamics. Harvesting is often assumed to be random in cases where there are no clear management goals in terms of sex and age composition of the harvest. However, recent studies have documented non-random off-take also in cases where this is not intended (see e.g. Bunnefeld et al. 2009). The reasons for such selective harvesting might vary between cases, but behavioural differences between age and sex classes are likely to predispose some classes for harvest mortality (Bischof et al. 2009). In long-lived species, such as most large carnivores, it is well known that long-term population growth rate is more sensitive to changes in adult female survival rates than to that of any other demographic rate (Eberhardt 2002; Gaillard et al. 2000). Thus, size- and ageselective harvest might have consequences that are unforeseen when assigning a quota harvest. Besides having a direct impact on the population development, selective harvesting regimes might also have unintended demographic side effects (Milner et al. 2007) and long-term evolutionary implications (Coltman et al. 2003).

The lynx population in Norway, along with most other European populations of large carnivores, experienced a drastic decline at the end of the nineteenth and early twentieth century leading to near extinction (Linnell et al. 2010). After this period, the lynx population in Norway expanded gradually for some decades before reaching its highest density around the mid-1990s (Linnell et al. 2010). This subsequently resulted in the demand for lynx hunting to be regulated through a quota system. The lynx is the largest wild felid species in Europe and displays only a moderate sexual size dimorphism (adult males $21 \mathrm{~kg}$ (SD, 1.7; $n=49$ ); adult females $16 \mathrm{~kg}$ (SD, $1.4 ; n=53)$; Odden and Linnell, unpublished data from Norway). However, behavioural differences between sex and age classes might also predispose classes for harvesting. Such differences might, for instance, arise due to higher risk taking (Bunnefeld et al. 2006) and larger home ranges (Linnell et al. 2001a) in male lynx. In response to this, separate female quotas in the lynx harvest have been allocated since the late 1990s in Norway. Although considerable effort has been spent in studying lynx ecology in Norway (Andrèn et al. 2006; Nilsen et al. 2010; Nilsen et al. 2009; Odden et al. 2006), so far little is known about the magnitude and composition of the harvest, and even less is known about the bag composition in relation to the standing population structure (Sæther et al. 2010).

This study seeks to explore important aspects of the lynx harvest in Norway. Firstly, we combined harvest statistics, monitoring data, and radio telemetry data and examined temporal trends in the age and sex composition of hunterkilled lynx in Norway during 1994-2009. Secondly, we examined the extent to which hunting was selective for different age and sex classes of lynx. Thirdly, we examined the extent to which hunters were able to respond to changes in quota size. Lastly, we reconstructed the population size of the lynx population based on cohort analysis of shot lynx. We then related these population estimates to the population estimates from the monitoring system which forms the backbone of the decision-making process in Norwegian lynx harvest. Although exploratory in nature, we contribute our study to help improve the sustainability of lynx harvest in Norway and beyond for the future.

\section{Methods}

Lynx harvest data

\section{Lynx hunting and monitoring in Norway}

Lynx have been managed through quota hunting since the mid-1990s. The general objective is to stabilise the population at politically determined regional goals which try to balance the need for viability with the limitation of conflicts (Linnell et al. 2010). Hunting is allowed in February and March within the strict limits of regionally specific quotas. Most lynx are shot following active pursuit and encirclement by large hunting teams that may or may not use a dog to drive the lynx past hunters waiting at posts. A few lynx are also killed in box traps (all information from Linnell et al. (2010)). The lynx population was monitored through a national monitoring programme which collects observations that indicate signs of reproduction during October-February (snow tracks from females with kittens and dead kittens) and applies a set of distance rules to separate different family groups from each other (Linnell et al. 2007). Quota decisions were made by regional boards consisting of elected politicians from the county parliaments (Sandström et al. 2009), and no formal rules or models for quota setting were applied. Because management regions have changed during the period (Linnell et al. 2010) and to ensure sufficient samples sizes within years, we analysed all data at the national level. Note that with this approach regions with highest lynx numbers and quotas will have the strongest influence on the results.

\section{Harvest data}

Data on harvested lynx in Norway from 1994 to 2009 were obtained through the Norwegian Large Predator Monitoring Program (www.rovdata.no), where hunters are required by hunting regulations to deliver lynx carcasses for postmortem examination. Also, rangers of the State Nature Inspectorate inspect a sample of field sites where lynx have 
been shot to verify the situation and circumstances of harvest. The lynx included in the analysis were from those shot in the quota hunting season in the period February through March. We obtained information about sex and age (determined by incremental lines in the tooth cementum; see Kvam 1984) based on autopsy of 1,019 individuals. In an average year, this represented $89 \%$ of lynx reported as harvested. Information on annual lynx quotas and bag size in Norway was obtained from the Internet pages of the Norwegian Directorate for Nature Management (www. dirnat.no) and Statistics Norway (www.ssb.no) during 2010. The harvest records are believed to be very accurate, at least for the legal harvest, although there is known to be a certain intensity of illegal killing in addition to mortality from other anthropogenic and non-anthropogenic sources (Andrèn et al. 2006).

\section{Data analysis}

\section{Statistical analysis of harvest numbers and composition}

In our initial analysis, we focused on the age and sex composition of the harvest using generalised linear models to investigate sex and age distributions in the harvest data. For analysis of variation in sex distributions, we assumed binomially distributed errors and used the logit link function. For analysis of variation in age at harvest, we assumed a Poisson distribution and used the log-link function. Linear models were used to model the relationship between annual quota size and bag size. We also examined the monitoring data and quota/bag size data for crosscorrelation, with and without time lags. Cross-correlations were determined using the ccf function in $\mathrm{R}$ ( $\mathrm{R}$ Development Core Team 2010). All analyses were performed in the R 2.12.1 software (R Development Core Team 2010).

\section{Population reconstruction analysis}

Based on the catch-at-age data described in the preceeding sections, we used cohort analysis (also known as virtual population analysis) to back-calculate the size of the Norwegian lynx population in the period 1994-2009 (Skalski et al. 2005). In the reconstruction, we defined February 1 (i.e. first day of hunting season) to be the start of the year and assumed that the quota harvest is a pulselike event taking place just at the start of the year, with natural mortality taking place throughout the rest of the year. The number-at-age $\left(N_{a, y}\right)$ can then be calculated as $N_{a, y}=N_{a+1, y+1} \exp (M)+h_{a, y}$, where $N_{a+1, y+1}$ is the number of individuals in the older age class the year after (i.e. the same cohort one year later), $M$ is the natural mortality coefficient (i.e. 1 -exp(natural mortality rate)), and $h_{a, y}$ is the number of animals of that age class harvested in year $y$.
Starting with the oldest age class (A), one then backcalculates the size of each cohort in a given year using the above equation. Total population size is then found by summing up the contribution from each cohort.

Standard cohort analyses are intended for complete cohorts (Solberg et al. 1999). This results in a substantial time-lag between data collection and the last possible reconstructed population size and structure for long-lived species. In our sample, the oldest lynx individual was 16 years, suggesting that standard methods were not suitable for our purpose. Thus, we applied the modified cohort analysis described in Ueno et al. (2009). Firstly, this method requires the definition of a $p+$ group, wherein all harvested individuals of the same sex are pooled (i.e. a composite age class). In our analysis, 5 years of age was used to define the $p^{+}$group, with about $80 \%$ of harvested female lynx and $87 \%$ of male lynx being harvested in younger age classes (i.e. age $0-4$ years). Secondly, the approach requires making assumptions about harvest rate in the $p+$ group relative to the next oldest age class $(p)$ (Ueno et al. 2009). As we only had access to 16 years of catch-atage data, we would not be able to conduct any statistical robust estimates of such a relationship, and we see no biological reason for any strong hunter selection between these age classes. Thus, we assumed that the harvest rate in the $p+$ group (i.e. lynx of 5 years of age or older) equalled that in the next oldest age group (i.e. lynx of 4 years of age; see model B-i in Ueno et al. (2009)). Thirdly, to be able to back-calculate the population size in $N_{p-\mathrm{y}}$, the size of $N_{p, y}$ +1 must be known or estimated. We opted to follow the model (model C) described in Ueno et al. (2009). Following this approach, the sum of the number-at-age in the plus-group for 1 year is assumed to be equal to the sum of the number-at-age within the plus-group for a particular cohort. Finally, to be able to estimate population sizes for recent years, assumptions have to be made about harvest mortality in the most recent year. In Ueno et al. (2009), three models are proposed: (A-i) rate of age-specific harvest mortality in most recent year is equal to the preceding year, (A-ii) the arithmetic mean of the three preceding years or (A-iii) during the seven preceding years. Initial analysis suggested that the size of the reconstructed population for the five most recent years was sensitive to the choice of model, and to avoid making subjective validation about which model to choose, we restricted further analysis of the reconstructed model to the years 1994-2004. Because our model contained six age classes, assumptions about harvest mortality during the last year did not affect the estimates prior to 2005 .

Estimation of annual non-harvest survival probabilities Estimated mean annual non-harvest survival probabilities used in the cohort analysis were based on data from 124 
(males: $n=62$, of which 16 were collared before 1 year of age; females: $n=62$, of which 18 were collared before 1 year of age) radio-collared lynx captured in southeastern and northern Norway. Details on capture and handling of lynx are described in Andren et al. (2006), in Arnemo et al. (2006), and at http://scandlynx.nina.no. All capture and handling were approved by Norwegian authorities. Our estimates of lynx survival probabilities are based on radiocollared individuals, and we opted to use telemetry-based methods to estimate survival (Murray 2006). As is common in wildlife telemetry studies, the individuals were captured and released at different times (i.e. delayed or staggered entry) and some individuals were lost due to e.g. collar failure before death (i.e. right censoring), rendering a simple binomial estimator for survival unreliable (see e.g. Murray 2006 and discussion therein). We thus used survival analysis implemented in the statistical software R 2.12.1 (R Development Core Team 2010) in the package survival (Therneau 2010). In the survival analysis, we assumed that the year started at February 1. In the current analysis, we estimated non-harvest mortality only (i.e. natural mortality), and we used the Non-parametric Cumulative Incidence Function (NCIFE) method (Heisey and Patterson 2006) to obtain unbiased estimates (see also Sandercock et al. (2011) for an application of the NCIFE method) because the lynx are faced with competing risks (harvest vs non-harvest mortality). Overall, we estimated an annual non-harvest mortality at $9.4 \%$ [95\% CI, 5.9-12.9] for radio-collared individuals. We used this estimate as a basis for our modified cohort analysis but also used upper and lower confidence limits to visualise the patterns. Note that our analysis reported in this study is concerned with patterns of lynx harvest from the whole of Norway, whereas data from radio-collared lynx were only available from certain regions in certain time windows. We thus did not explore further mortality patterns of our radio-collared lynx here, as these have been reported previously in Andrèn et al. (2006) based partly on the same data. The purpose of the radio-telemetry data here was solely to estimate non-harvest mortality rates for use in the population reconstruction.

Statistical analysis of the reconstructed population To further investigate the extent of sex and age selectivity in the lynx harvest in Norway, we used the estimates of $N_{p}$, $y$ from the modified cohort analysis described above as an estimate of the age distribution of the standing population just prior to the quota harvest season. Age- and sex-specific harvesting rates were then estimated by dividing the number of harvested individuals in the different age and sex classes by the number of individuals estimated to be alive in that age and sex class by the modified cohort analysis. Before further analysis, we applied arcsine transformation (Sokal and Rohlf 1995) on the estimated
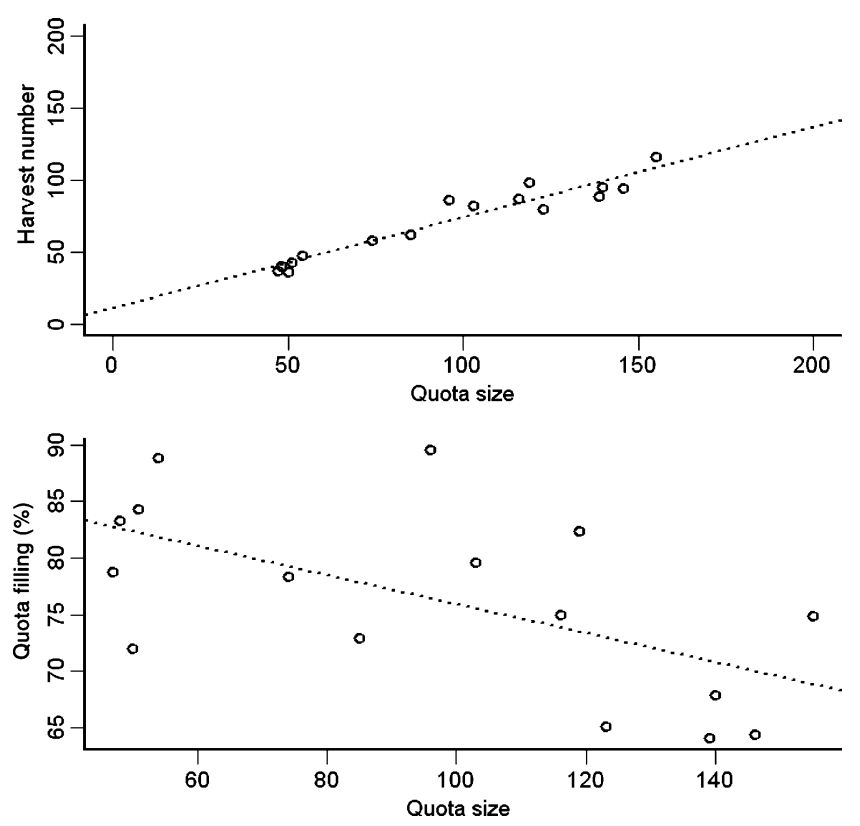

Fig. 1 Top panel, relationship between realised harvest numbers and quota. Bottom panel, quota and hunting success (i.e. percentage quota filling)

harvest proportions, ensuring that the model-based estimates of harvesting rates and corresponding confidence limits were in the range [0-1]. The estimates were backtransformed prior to reporting and plotting. To account for the overall variation in hunting pressure among years, we used linear mixed effects models implemented with the lmer-function in R ad-on library lme4 (Bates et al. 2010) when examining the potential for different harvest rates among sex and age classes. In the models, year was fitted as a random (intercept) term, with age and sex fitted as fixed effects.

\section{Results}

Temporal trends in Norwegian lynx harvest

In general, there was a very close relationship between assigned quotas and reported catch $(r=0.96, p<0.005$; Fig. 1a), clearly showing that the quota level has a strong impact on actual harvest. Overall, the degree of quota filling was $76 \% \pm 2.2 \mathrm{SE}$, but there was some indication of a lower quota filling with increasing quotas $(\beta=-0.13, t=$ $2.81, p=0.014$; Fig. $1 \mathrm{~b}$ ). The quota levels responded to changes in population estimates, but there were clear indications of time lags in the quota harvest. This resulted in strong signals of cross-correlations between the minimum number of family groups (used by the managers as an index of population size) and harvest quotas, and these signals were 
stronger with time lags than without lags, with Pearson crosscorrelation coefficients estimated at 0.43 (no lag), 0.64 (quotas 1 year lagged) and 0.65 (quotas 2 years lagged).

Age- and sex-specific composition of the harvest bag

Overall, there is a clear indication that the lynx harvest was slightly male-biased considering the period in general $(p<$ 0.005 ; logistic regression) with the probability of a harvested lynx being a female estimated to be $44 \%$ [ $95 \%$ CI, 41-47\%]. There was no significant trend in increasing male bias in the harvest over the period $(\beta=0.018$; SE, $0.014, p=0.190$; logistic regression). The predicted mean age of hunter-killed lynx in Norway was 2.9 years $(95 \% \mathrm{CI}$, 2.8-3.0). There was however a significant difference between the mean age of harvested males and females ( $p$ $<0.001$; Poisson regression); the predicted mean age of males was 2.7 years $(95 \% \mathrm{CI}, 2.6-2.9)$, and the predicted mean age of harvested females was 3.1 (95\% CI, 2.9-3.2).

Analysis based on the reconstructed population

In general, the reconstruction of the Norwegian lynx population from 1994 to 2004 fitted well with the patterns reported from the national lynx monitoring programme based on observations of lynx family groups (i.e. females accompanied by their dependent offspring; Andrèn et al. 2002) (Fig. 2a, b). The Pearson correlation coefficient between the population estimates from the reconstructed population and those from the monitoring programme was $r=0.84(p=0.005)$.

Based on the reconstructed population, we further examined patterns of age- and sex-selective harvest in the period 1994-2004. Mean harvest rates (i.e. \% of standing population removed by harvest) varied considerably between years (from $13.2 \%$ in 1994 to $31.8 \%$ in 2002). In general, harvest rates were higher among males than among females during this period (males, 24.4\% [95\% CI, 19.329.8]; females, 18.2\% [95\% CI, 15.1-21.4]; Fig. 3), and a linear mixed effects model (with a random intercept term for year to control for different overall hunting pressures between years) clearly revealed a higher risk of hunting mortality in males $(p<0.001$; linear mixed effects model; Fig. 3). Among males, there was a clear pattern of age selectivity in the harvest when comparing the youngest age class (kittens at approximately $8-10$ months at the time of harvest) with older lynx ( $p=0.006$; linear mixed effects model; Fig. 3). However, this effect was due to lower harvest rates among kittens, and when comparing only the older age classes we did not find any evidence for selectivity ( $p=0.817$; linear mixed effects model). Among females, no pattern of selective harvest was evident when comparing harvest rates for kittens with that of older age classes ( $p=$ 0.905; linear mixed effects model; Fig. 3), and neither were
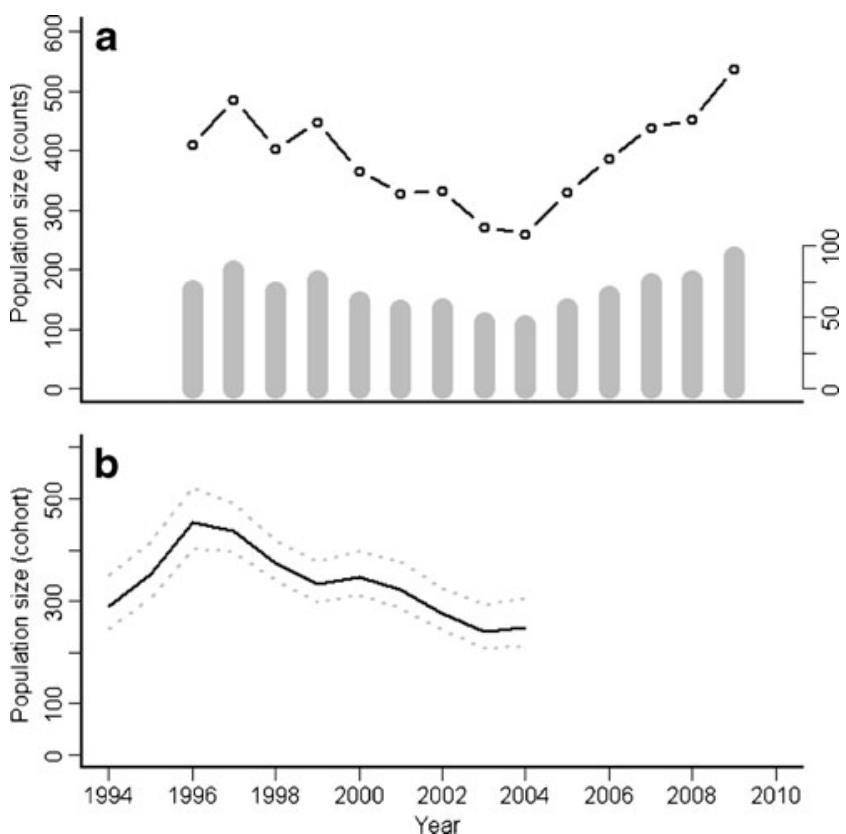

Fig. 2 a Estimated total lynx population size in Norway in 19962009 based on the Norwegian Large Predator Monitoring Program, with the reported minimum number of lynx family groups represented by grey bars (right y-axis). b Estimated lynx population size based on modified cohort analysis (Ueno et al. 2009) for the period 1994-2004. Solid black line depicts the estimates when the population is reconstructed assuming the background mortality rate as calculated from the data (see "Methods"), with dotted grey lines depicting the size of the reconstructed population when assuming background mortality rates at the upper (12.9\%) and lower (5.6\%) confidence limits

there any differences between age classes among the older age classes ( $p=0.227$; linear mixed effects model).

\section{Discussion}

Our analysis of lynx harvest in Norway revealed at least five important points about lynx harvest in Norway: Firstly,

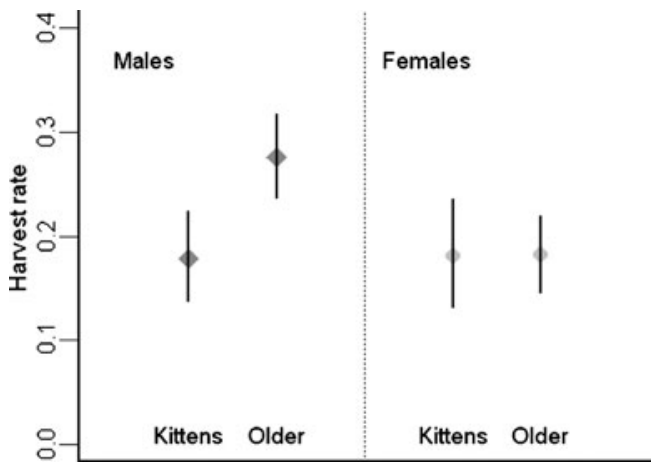

Fig. 3 Estimates of harvest rates based on modified cohort analysis for male (left) and female (right) lynx in Norway in the period 1994 2005. The risk of harvest mortality is significantly higher for male lynx, and among male lynx the risk is higher for adults compared to kittens (see "Results"). Error bars represent 95\% CI 
(1) there was clear evidence for sex-selective harvesting, with males experiencing a higher rate of harvest mortality than females, and (2) we found evidence for age-specific harvest rates among males but not among females. Furthermore, (3) there was a very close relationship between assigned quotas and actual harvest off-take, and the harvest success is generally high (mean $=76 \%$ ). This suggests that the quotas set by the managers have a strong effect on the actual off-take. Lastly, (4) the monitoring method based on family group counts was very closely related to an independent estimate of population size, which indicates that managers have access to a good monitoring tool. Despite this, (5) there was a time lag between population size and the size of the quota-based harvest. Recent theoretical and empirical work (Fryxell et al. 2010) has shown that such harvesting regimes are likely to induce cyclic or unstable population dynamics. To what extent the current regime will generate regular cycles in the case of the Norwegian lynx population is currently unclear and not possible to determine given the relatively short time series available on population abundance. Our results might suggest that one of the major factors associated with the generation of cycles is present in Norwegian lynx management.

Harvesting regimes selecting for certain age and sex classes have received growing attention from managers and biologists (Milner et al. 2007; Proaktor et al. 2007), due to their effect on population dynamics (Milner et al. 2007) and evolutionary processes (Proaktor et al. 2007). Often, management agencies typically skew harvest towards males (Milner et al. 2006; Milner et al. 2007), and the implications for such harvesting regimes have received much attention (Mysterud et al. 2002; Milner et al. 2007; Swenson et al. 1997). In contrast to many ungulate management schemes, lynx harvest in Norway is not specified by age- or sex-specific quotas, although a maximum number of adult females in the quota is often specified (Linnell et al. 2010). Our analysis nevertheless revealed an uneven risk of hunting mortality among age and sex classes. Firstly, males in general had higher harvesting pressure than females, and among males harvesting pressure was higher for yearling and adult lynx than it was for kittens. The higher hunting mortality among males will typically manifest itself in a biased adult sex ratio (Milner et al. 2007) and a younger male age structure (Stoner et al. 2006). We do not know why young-of-the-year males had lower risk of hunting mortality, but we might speculate that since they almost always are in company with their mother during the harvesting season they will also experience the same risk as their mother. In support of this, they had harvest rates similar to that of females.

It is very difficult, if not impossible, to evaluate the age and sex of a lynx during a hunting situation, implying that once the lynx is encountered the hunters have limited ability to be selective. However, the hunters might have to decide if they are going to pursue a track from a family group (adult female with kittens) or a track from a single lynx (adult male or adult female without kittens). When pursuing a family group, it is purely chance if they kill a male or female kitten or the mother, probably explaining the equal mortality rates of the sexes in this age class. If the hunters want to avoid filling the female sub-quota (i.e. they want to maximise their hunting chances, and as soon as the female sub-quota is filled all hunting stops within the region), we might speculate that they tend to focus their effort on single lynx, which removes some of the pressure on adult females (at least those with dependent kittens). Among solitary lynx, it is likely that adult males are more detectable because they move more (which increases their chance of being detected, via their tracks, and then pursued) (Jedrzejewski et al. 2002) and appear to take greater risks than females (Bunnefeld et al. 2006) by using areas close to roads and houses where they risk detection (Sunde et al. 1998). Recent models indicate that male off-take rates might play a larger demographic role than initially anticipated, an effect that is strongly dependent on the social system (Caro et al. 2009) and probably also on the population density. While reduced fertility due to lack of males is probably rare (Milner-Gulland et al. 2003), more subtle effects have been observed in e.g. ungulates (Solberg et al. 2002). The effect of male-biased harvesting in Norwegian lynx is still poorly understood but is deserving of study because of the overlap between the hunting season and the mating season.

Our results revealed that the Norwegian quota harvest system is relatively successful in terms of reaching the set quotas. Overall, the Norwegian lynx hunters harvested $76 \%$ of the quota, but comparison to other studies is precluded by a lack in studies reporting the degree of quota filling for mammalian carnivore systems. However, a recent study suggests that quota filling in large carnivore harvest is highly variable between situations ranging from $<50 \%$ to almost complete filling of the quota (Bischoff et al., manuscript submitted for publication). Further, our analysis provides some indication that the harvest success decreased with increasing quotas. This probably reflects a limit in the capacity of the effective hunting teams to respond to the increased hunting opportunities given the technical and physical demands of this hunting form.

Our reconstruction of the Norwegian lynx population using the modified cohort analysis developed by Ueno et al. (2009) revealed patterns in population development that strongly resembled those based on the National Predator Monitoring Program (Linnell et al. 2010). Overall, this suggests that the management of Norwegian lynx should be based on a relatively good knowledge about the underlying population size, thus representing one of only a few cases where large carnivore monitoring programmes have been validated (Anderson and Lindzey 2005). Nevertheless, as is always the case for such reconstructions, assumptions about 
non-harvest mortality rates will have a strong effect on the estimated population sizes (Skalski et al. 2005). We used a large sample of radio-collared lynx to obtain unbiased estimates of non-harvest mortality rates but did not take into account any inter-annual or regional differences in nonharvest mortality. Such differences might arise e.g. due to different levels of illegal harvest (Andrèn et al. 2006) or other sources of natural mortality. Thus, while our reconstruction of the Norwegian lynx population should not be seen as a formal test of the monitoring programme of lynx in Norway, it clearly suggests that the current programme track the changes in lynx population size reasonably well and that the extrapolated population size (Andrèn et al. 2002) is reasonable. Interestingly, due to the nature of cohort analysis, should one argue that the current monitoring programme greatly underestimates the true population size (which might happen due to detection rates that are less than 1), it also implies that the non-harvest mortality rate used in our analysis is greatly underestimated. This is not a likely scenario for a relatively long-lived species such as lynx, unless other human-related mortalities are underestimated.

We also call for some caution when interpreting this result in terms of practical management. Norwegian lynx management is subdivided into eight distinct subunits (Linnell et al. 2010), each with their predetermined management goals (Sandström et al. 2009). While our modelling of the total Norwegian lynx population give us grounds to have confidence in the monitoring system, demographic stochasticity and sampling variance should be expected to play a much larger part in smaller populations, such as those within a given management region. With management goals for the eight management units ranging from 5 to 12 annual reproductions, demographic variance and sampling variance could be expected to be substantial (Lande et al. 2003; Doak et al. 2005). Further, the size of the reconstructed population was sensitive to the choice of parameters used to describe natural mortality, with higher natural mortality yielding a larger reconstructed population. Although the ongoing telemetry-based research projects in Norway are constantly producing improved estimates of these crucial parameters, the existence of unpredictable factors (Andrèn et al. 2006) implies that there will always be much uncertainty in these parameters. When age estimation is done by counting incremental lines in the tooth cementum, there are possibilities for errors in classification, especially for older individuals (Diefenbach et al. 1998; Costello et al. 2004). However, by grouping all individuals with an estimated age between 5 and 16 years to the $p^{+}$group in the analysis, the effect of possible misclassifications of older animals should be negligible.

Despite managers having access to relatively precise monitoring data, the population trajectories based on both the reconstructed population estimates and the monitoring programme showed that the estimated population size varied during the period of lynx quota harvesting in Norway. While the proximate cause of these fluctuations is probably a high degree of inter-annual variation in harvest rate, the ultimate cause probably is in the time lag in the management process. The fact that such time lags can trigger fluctuations in wildlife populations is well established (Fryxell et al. 2010). Contributing to this time lag, the current year quotas set by the managers are based on the previous year's population estimates. Current year counts are not available at the time the quota is set because lynx monitoring is still ongoing when the hunt starts, suggesting that a method to build this effect into current management models might therefore reduce the fluctuations in the lynx population. Our knowledge of lynx ecology and predator dynamics suggests that it is not likely that these fluctuations being due to any environmental changes other than hunting pressure.

In retrospect, our analysis indicates that managers should be able to regulate lynx harvest at a sustainable level but that further decision-making tools might assist in this endeavour. Sampling variation in population censuses and time lags in the management processes are likely to be the main challenges for sustainable and stable lynx management in Norway. Our results should point the way to improvements in lynx management in Norway, with a key message being that managers should trust the monitoring data and react faster to observed changes. This analysis also illustrates the need to go beyond biology-only models (Sæther et al. 2010) when seeking to develop a practical harvest model for Norwegian lynx management. The documentation of time lags and indications of hunter saturation indicate a need to include both biological and institutional factors into a holistic decision-making framework (Milner-Gulland 2011; Bunnefeld et al. 2011).

Acknowledgements This study is based on data from the Norwegian Large Predator Monitoring Program financed by the Ministry of the Environment through the Directorate for Nature Management in Norway. The analysis was funded by the Directorate for Nature Management, the Research Council of Norway and the European Union's 7th Framework Programme. We are grateful to Frode Holmstrøm and May I. Solem for conducting the post-mortem examinations and tooth sectioning and to two anonymous referees for valuable comments on a previous draft.

Open Access This article is distributed under the terms of the Creative Commons Attribution Noncommercial License which permits any noncommercial use, distribution, and reproduction in any medium, provided the original author(s) and source are credited.

\section{References}

Anderson CR, Lindzey FG (2005) Experimental evaluation of population trend and harvest composition in a Wyoming cougar population. Wildl Soc Buletin 33:179-188

Andrèn H, Linnell JDC, Liberg O, Ahlqvist $\mathrm{P}$, Andersen R, Danell A, Franzen R, Kvam T, Odden J, Segerstrom P (2002) Estimating total lynx Lynx lynx population size from censuses of family groups. Wildl Biol 8(4):299-306 
Andrèn H, Linnell JDC, Liberg O, Andersen R, Danell A, Karlsson J, Odden J, Moa PF, Ahlqvist P, Kvam T, Franzen R, Segerstrom P (2006) Survival rates and causes of mortality in Eurasian lynx (Lynx lynx) in multi-use landscapes. Biol Conserv 131(1):23-32

Arnemo JM, Ahlqvist P, Andersen R, Berntsen F, Ericsson G, Odden J, Brunberg S, Segerstrom P, Swenson JE (2006) Risk of capturerelated mortality in large free-ranging mammals: experiences from Scandinavia. Wildl Biol 12(1):109-113

Bates D, Maechler M, Bolker B. (2010) lme4: Linear mixed-effects models using S4 classes. R package version 0.999375-41. http:// CRAN.R-project.org/package $=$ lme 4

Bischof R, Swenson JE, Yoccoz NG, Mysterud A, Gimenez O (2009) The magnitude and selectivity of natural and multiple anthropogenic mortality causes in hunted brown bears. J Anim Ecol 78 (3):656-665. doi:10.1111/j.1365-2656.2009.01524.x

Bunnefeld N, Linnell JDC, Odden J, van Duijn MAJ, Andersen R (2006) Risk taking by Eurasian lynx (Lynx lynx) in a humandominated landscape: effects of sex and reproductive status. J Zool 270(1):31-39

Bunnefeld N, Baines D, Newborn D, Milner-Gulland EJ (2009) Factors affecting unintentional harvesting selectivity in a monomorphic species. J Anim Ecol 78(2):485-492. doi:10.1111/ j.1365-2656.2008.01500.x

Bunnefeld N, Hoshino E, Milner-Gulland EJ (2011) Management strategy evaluation: a powerful tool for conservation? Trends Ecol Evol 26(9):441-447

Caro TM, Young CR, Cauldwell AE, Brown DDE (2009) Animal breeding systems and big game hunting: models and application. Biol Conserv 142(4):909-929. doi:10.1016/j.biocon.2008.12.018

Coltman DW, O'Donoghue P, Jorgenson JT, Hogg JT, Strobeck C, Festa-Bianchet M (2003) Undesirable evolutionary consequences of trophy hunting. Nature 426:655-658

Costello CM, Inman $\mathrm{KH}$, Jones DE, Inman RM, Thompson $\mathrm{BC}$, Quigley HB (2004) Reliability of the cementum annuli technique for estimating age of black bears in New Mexico. Wildl Soc Bull 32(1):169-176

Diefenbach DR, Harshyne WA, Alt GL, Matson GM (1998) Analysis of error from cementum-annuli age estimates of known-age Pennsylvania black bears. J Wildl Manage 62(4):1281-1291

Doak DF, Gross K, Morris WF (2005) Understanding and predicting the effects of sparse data on demographic analyses. Ecology 86 (5):1154-1163

Eberhardt LL (2002) A paradigm for population analysis of long-lived vertebrates. Ecology 83(10):2841-2854

Fryxell JM, Packer C, McCann K, Solberg EJ, Sæther BE (2010) Resource management cycles and the sustainability of harvested wildlife populations. Science 328:903-906

Gaillard JM, Festa-Bianchet M, Yoccoz NG, Loison A, Toigo C (2000) Temporal variation in fitness components and population dynamics of large herbivores. Annu Rev Ecol Syst 31:367-393

Heisey DM, Patterson BR (2006) A review of methods to estimate cause-specific mortality in presence of competing risks. J Wildl Manage 70(6):1544-1555

Hiedanpää J, Bromley DW (2011) The harmonization game: reasons and rules in European biodiversity policy. Environ Policy Gov 21:99-111

Huber D, Kusak J, Majik-Skribinsek A, Majnarik D, Sindicic M (2008) A multidimensional approach to managing the European brown bear in Croatia. Ursus 19:22-32

Jedrzejewski W, Schmidt K, Okarma H, Kowalczyk R (2002) Movement pattern and home range use by the Eurasian lynx in Bialowieza Primeval Forest (Poland). Ann Zool Fenn 39(1):29-41

Kvam T (1984) Age determination in European lynx Lynx lynx by incremental lines in tooth cementum. Acta Zool Fennica 171:221-223

Lande R, Engen S, Sæther BE (2003) Stochastic population dynamics in ecology and conservation. Oxford series in ecology and evolution, 1st edn. Oxford University Press, Oxford
Linnell JDC, Andersen R, Kvam T, Andren H, Liberg O, Odden J, Moa PF (2001a) Home range size and choice of management strategy for lynx in Scandinavia. Environ Manag 27(6):869-879

Linnell JDC, Swenson J, Andersen R (2001b) Predators and people: conservation of large carnivores is possible at high human densities if management policy is favorable. Anim Conserv 4:345-350

Linnell JDC, Odden J, Andren H, Liberg O, Andersen R, Moa P, Kvam T, Broseth H, Segerstrom P, Ahlqvist P, Schmidt K, Jedrzejewski W, Okarma H (2007) Distance rules for minimum counts of Eurasian lynx Lynx lynx family groups under different ecological conditions. Wildl Biol 13(4):447-455

Linnell JDC, Salvatori V, Boitani L (2008) Guidelines for population level management plans for large carnivores in Europe. Large Carnivore Initiative for Europe

Linnell JDC, Brøseth H, Odden J, Nilsen EB (2010) Sustainably harvesting a large carnivore? Development of Eurasian lynx populations in Norway during 160 years of shifting policy. Environ Manag 45:1142-1154

Milner JM, Bonenfant C, Mysterud A, Gaillard JM, Csanyi S, Stenseth NC (2006) Temporal and spatial development of red deer harvesting in Europe: biological and cultural factors. J Appl Ecol 43(4):721-734

Milner JM, Nilsen EB, Andreassen HP (2007) Demographic side effects of selective hunting in ungulates and carnivores. Conserv Biol 21(1):36-47

Milner-Gulland EJ (2011) Integrating fisheries approaches and household utility models for improved resource management. Proc Natl Acad Sci U S A. doi:10.1073/pnas.1010533108

Milner-Gulland EJ, Bukreevea OM, Coulson T, Lushchekina AA, Kholodova MV, Bekenov AB, Grachev IA (2003) Reproductive collapse in saiga antelope harems. Nature 422:135-135

Murray DL (2006) On improving telemetry-based survival estimation. J Wildl Manage 70(6):1530-1543

Mysterud A, Coulson T, Stenseth NC (2002) The role of males in the dynamics of ungulate populations. J Anim Ecol 71(6):907-915

Nilsen EB, Linnell JDC, Odden J, Andersen R (2009) Climate, season, and social status modulate the functional response of an efficient stalking predator: the Eurasian lynx. J Anim Ecol 78 (4):741-751. doi:10.1111/j.1365-2656.2009.01547.x

Nilsen EB, Broseth H, Odden J, Linnell JDC (2010) The cost of maturing early in a solitary carnivore. Oecologia 164(4):943948. doi:10.1007/s00442-010-1713-2

Odden J, Linnell JDC, Andersen R (2006) Diet of Eurasian lynx, Lynx lynx, in the boreal forest of southeastern Norway: the relative importance of livestock and hares at low roe deer density. Eur J Wildl Res 52(4):237-244

Proaktor G, Coulson T, Milner-Gulland EJ (2007) Evolutionary responses to harvesting in ungulates. J Anim Ecol 76(4):669678. doi:10.1111/j.1365-2656.2007.01244.x

R Development Core Team (2010) R: a language and environment for statistical computing. R Foundation for Statistical Computing, Vienna

Sæther BE, Engen S, Odden J, Linnell JDC, Grotan V, Andren H (2010) Sustainable harvest strategies for age-structured Eurasian lynx populations: the use of reproductive value. Biol Conserv 143(9):1970-1979

Sandercock BK, Nilsen EB, Broseth H, Pedersen HC (2011) Is hunting mortality additive or compensatory to natural mortality? Effects of experimental harvest on the survival and cause-specific mortality of willow ptarmigan. J Anim Ecol 80(1):244-258. doi:10.1111/j.1365-2656.2010.01769.x

Sandström C, Pellikka J, Ratamäki O, Sande A (2009) Management plans of large carnivores in Fennoscandia: new patterns of regional participation. Hum Dimens Wildl 14:37-50

Skalski JR, Ryding KE, Millspaugh J (2005) Wildlife demographyanalysis of sex, age, and count data. Academic, San Diego

Sokal RR, Rohlf FJ (1995) Biometry, 3rd edn. Freeman, New York 
Solberg EJ, Saether B-E, Strand O, Loison A (1999) Dynamics of a harvested moose population in a variable environment. J Anim Ecol 68:186-204

Solberg EJ, Loison A, Ringsby TH, Saether BE, Heim M (2002) Biased adult sex ratio can affect fecundity in primiparous moose Alces alces. Wildl Biol 8(2):117-128

Stoner DC, Wolfe ML, Choate DM (2006) Cougar exploitation levels in Utah: implications for demographic structure, population recovery, and metapopulation dynamics. J Wildl Manage 70(6):1588-1600

Sunde P, Overskaug K, Kvam T (1998) Culling of lynxes (Lynx lynx) related to livestock predation in a heterogenous landscape. Wildl Biol 4:169-175

Swenson JE, Sandegren F, Soderberg A, Bjarvall A, Franzen R, Wabakken P (1997) Infanticide caused by hunting of male bears. Nature 386(6624):450-451
Swenson J, Sandegren F, Bjärvall A, Wabakken P (1998) Living with success: research needs for an expanding brown bear population. Ursus 22:17-23

Therneau T (2010) Survival: survival analysis, including penalised likeliood. R package version 2.36-5. http://CRAN.R-project.org/ package $=$ survival

Treves A (2009) Hunting for large carnivore conservation. J Appl Ecol 46(6):1350-1356. doi:10.1111/j.1365-2664.2009.01729.x

Trouwborst A (2010) Managing the carnivore comeback: international and EU species protection law and the return of lynx, wolf and bear to western Europe. J Environ Laws 22:347372

Ueno M, Matsuishi T, Solberg EJ, Saitoh T (2009) Application of cohort analysis to large terrestrial mammal harvest data. Mamm Study 34(2):65-76 